v. 2, n. 2, mai.lago, 2019

REVISTA ENSINO DE GEOGRAFIA (RECIFE)

\title{
EDUCAÇÃO GEOGRÁFICA, ECOFORMAÇÃO E ECOCIDADANIA: A BUSCA POR UMA SABEDORIA
}

\author{
Lucas Antônio Viana Botêlho \\ Discente de Doutorado (PPGeo/UFPE) \\ lucasviana.botelho@gmail.com \\ ORCID Id: https://orcid.org/0000-0002-9426-5602 \\ Francisco Kennedy Silva dos Santos \\ Professor do Programa de Pós-Graduação em Geografia da UFPE \\ kennedyufpe@gmail.com \\ ORCID iD: https://orcid.org/0000-0002-4431-5632
}

Artigo recebido em 19/04/2019 e aceito em 14/06/2019

\begin{abstract}
RESUMO: Em face das necessidades do presente século, em que o ensino de Geografia requer uma ruptura necessária com a permanente cisão conteudista entre homem e natureza, ainda programada em seus roteiros pedagógicos, a ecoformação e a ecocidadania apresentam-se como tendências articuladoras e propositoras de trajetórias reformuladoras, que mergulham nas tramas contemporâneas que urgem por respostas ativas transformadoras. Neste sentido, o presente texto, de natureza teórico-reflexiva, suscita a necessidade de (re)pensar e, diante disto, propor outros roteiros não normativos para a educação geográfica, os quais promovam uma sabedoria geográfica, tecendo convergências analíticas e críticas entre o saber social (o entendimento da sociedade) e o saber ambiental (o entendimento da natureza) por intermédio de um diálogo entre a ecoformação e a ecocidadania. Nosso intuito, é possibilitar uma compreensão situada nos termos da ecoformação e da ecocidadania para a formulação de práticas outras na formação em Geografia.
\end{abstract}

Palavras-chave: Geografia Escolar; Ecocidadania; Ecoformação.

\section{GEOGRAPHICAL EDUCATION, ECOFORMATION AND ECOCIDADANIA: THE SEARCH FOR WISDOM}

\begin{abstract}
In the face of the needs of the present century, in which the teaching of geography requires a necessary break with the permanent contentious split between man and nature, still programmed in its pedagogical scripts, ecoformation and ecocity are presented as articulating tendencies and proposers of trajectories. reformulators, who delve into the contemporary plots that urge for transformative active responses. In this sense, the present theoretical-reflexive text raises the need to (re) think and, therefore, propose other non- normative scripts for geographic education, which promote a geographical wisdom, weaving analytical and critical convergences between social knowledge (the understanding of society) and environmental knowledge (the understanding of nature) through a dialogue between eco- training and eco-citizenship. Our aim is to enable an understanding situated in terms of ecoforming and eco-citizenship for the formulation of other practices in geography training..
\end{abstract}

Keywords: School Geography; Ecocitizenship; Ecoforming 


\section{DE ONDE PARTIMOS - UMA INTRODUÇÃO AO PENSAR}

Nosso horizonte, ao pensar num processo educativo ambiental, é a busca por uma formação humana, ou seja, que busque formar o sujeito, enquanto indivíduo-coletivo, como partícipe de uma trama societária em permanente estado de vir a ser. Buscamos tecer um diálogo necessário, por entre os meandros da Geografia escolar contemporânea, que desvirtue uma lógica separatista e estruturalista entre saberes sociais e saberes ambientais, promovendo numa sabedoria geográfica, permeada pela criticidade e pela reflexividade como princípios norteadores.

Partimos de um diálogo iniciado com a pesquisa intitulada "A ecocidadania como princípio formativo e propositivo: diálogos necessários para construção de uma escola cidadã”, dissertação de mestrado defendida em fevereiro de 2017, na qual foi possível entretecer o ideário da ecocidadania com a Geografia escolar e a proposta da escola cidadã, que emerge como eixo norteador para o estreitamento de diálogos e propostas entre a Geografia escolar e a ecocidadania, tendência que movimenta as práticas educativas socioambientais. Intentando, assim, (re)pensar estratégias didático-pedagógicas ecoformadoras para o tempo presente, um tempo que urge um outro ensinar-aprender nas escolas, amplia-se os horizontes deste diálogo por intermédio deste texto.

No entanto, percebeu-se na coleta de dados, que se deu por meio de entrevistas com os professores imersos nestas práticas formativas que visam a construção de uma consciência socioambiental, algumas lacunas formativas no tocante a Educação Ambiental quanto ao professor de Geografia. Estas lacunas se fizeram sentir, principalmente, pelo fato de o mesmo não se envolver com os projetos pedagógicos que a escola desenvolve e executa, os quais versam sobre questões socioambientais, em sua maioria enfocadas no bairro onde a escola está situada. Nitidamente, o professor vem detendo sua prática apenas nos trâmites diários e cíclicos da sala de aula, não oportunizando o que aqui nominamos de sabedoria geográfica, ideia que desenvolveremos no decorrer das discussões e que se entrelaça aos próprios sentidos e significados da formação inicial de professores.

Entendemos a falta que há, no âmbito cursos de formação inicial de professores de Geografia, de um debate crítico-reflexivo-mobilizador em torno de questões socioambientais, sobretudo em virtude de esta ser uma disciplina que se volta tanto ao entendimento das dinâmicas societárias quanto dos elementos e aspectos ambientais e como estas duas dimensões se arranjam e constituem o objeto científico-pedagógico desta ciência: o espaço geográfico (SANTOS, 1996; VESENTINI, 1997). A necessidade de dar respostas às práticas 
desenvolvidas pelos professores em seus contextos didáticos é tão grande, e necessária, que muitas vezes nos passa desapercebida a igual necessidade de tematizar e problematizar que formação, quer seja inicial quer seja continuada - muito embora compreendamos aqui a formação como uma amálgama mais ampla, que tem um início e se desdobra a partir dos movimentos na/da prática, em continuidade - conduziu este profissional do ensino até aquele momento de sua jornada.

Além disto, a disciplina escolar de Geografia apregoa, curricularmente falando, a formação cidadã como uma de suas bandeiras de atuação e como uma das bases para confecção de suas práticas, porém ainda é algo que não se torna efetivo nos cenários escolares, não por um "não-querer" dos professores, mas pela ausência de um conjunto de questões pedagógicas e estruturais que tornem possível a materialização de práticas escolares geográficas que promovam aprendizagens geradoras de uma sabedoria geográfica, que é socioambiental em seu cerne (BOTÊLHO; SANTOS; SANTOS, 2016).

Diante destas problematizações iniciais que nos trazem até aqui, intentamos através deste texto propor outros roteiros não normativos para a educação geográfica, tanto na escola quanto nos cursos de formação de professores, promovendo uma sabedoria geográfica, ao buscar convergências analítico-reflexivas entre o saber social (o entendimento da sociedade) e o saber ambiental (o entendimento da natureza), discutidos por Leff (2009), por intermédio de um diálogo com a ecoformação e a ecocidadania, enquanto perspectivas que nutrem esperanças que nos movam noutraS direções. De natureza teórico-reflexiva, este texto apresenta um ensaio, pautado no diálogo com referências que ilustram os eixos temáticos que aqui buscamos abarcar e que mobilizam o debate e as proposições a serem construídas no decorrer deste.

\section{UM ENCONTRO DA EDUCAÇÃO AMBIENTAL COM A EDUCAÇÃO GEOGRÁFICA: abrindo trilhas à sabedoria geográfica}

Quando nos detemos a refletir sobre os pressupostos epistemológicos da Geografia, iniciamos um debate que mergulha numa miríade de questões de ordem social e natural que precisam ser levadas em consideração para a compreensão de seu objeto de estudo: o espaço geográfico. Este espaço é tão social quanto natural, e estas dimensões são indissociáveis (SUERTEGARAY, 2003), não havendo como formular a ideia de espaço sem cogitar os arranjos concebidos entre os aspectos e elementos da natureza sobre os quais as antropossociedades (SOFFIATI, 2008) se erguem e se desenvolvem, em seus aspectos econômicos, políticos, sociais e culturais. 
A recolocação do homem na natureza e da natureza no homem, tal como nos diz Fraga (2016), é uma necessidade contemporânea que emerge em meio a um cenário caótico, de crise (ESTEVES, 2011), de risco (BECK, 1992), de colapso socioambiental. Para isto, é preciso romper com o que é pensado sobre a natureza. Com uma representação capitalizada e objetificadora de natureza. A natureza não é objeto, não é instrumento, não é "coisa" manipulável e a serviço do homem, de sua incansável marcha pelo progresso em diferentes frentes de avanço técnico-científico-informacional, como argumentado por Santos (1996).

Tal como afirma Reigota (2008), a natureza não está além do homem, como algo fora dele, pois é ele mesmo parte dela, constituinte de seus processos ecológicos, assim como a natureza está para ser meio através do qual o homem se alça em sua jornada social, científica, política, econômica e humanitária. Ao pensarmos nisto, compreendemos que homem e natureza não constituem dimensões distanciadas, mas que convergem em determinado momento da trajetória da humanidade para surgir o que chamaremos de meio ambiente, tal como estruturamos na figura 1.

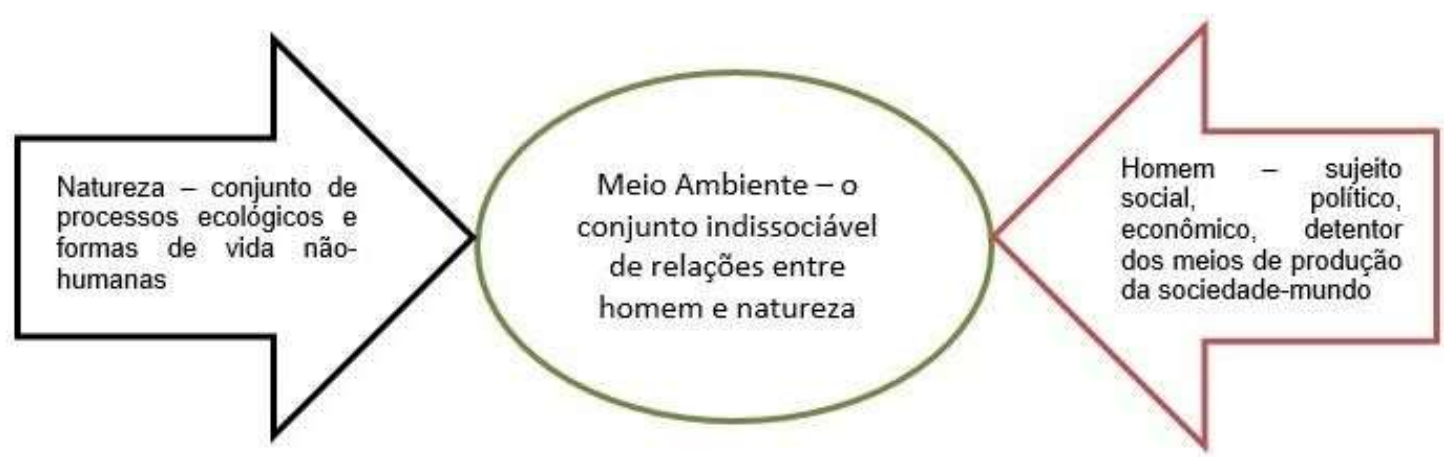

Figura 1 - A constituição de nossa leitura do que significa meio ambiente.

Fonte: elaborado pelo autor, 2019.

Como demonstrado na figura 1 , nosso entendimento acerca de meio ambiente está atrelado a uma leitura contemporânea, na qual não é mais possível conceber uma indissociabilidade entre homem e natureza, como a tradição positivista apregoou, ao defender o separatismo estruturalista entre sujeito e objeto, sobrepondo o homem a natureza. Nossa leitura crítica acerca do conceito de meio ambiente, diz respeito a compreensão de que não há cisão entre o homem, enquanto sujeito social-político-econômico-ambiental no mundo, e a natureza, há muito coisificada e objetificada, uma entidade externa a sociedade (NARDY; DEGASPERY, 2016).

Estamos nos situando numa leitura balizada e embasada numa compreensão de Morin, Ciurana e Motta (2003, p. 95), quando nos apresentam a ideia de "sociedade-mundo", embora 
ainda considerada pelos autores como "[...] em gestação inacabada, submetida a forças destrutivas/criativas e, talvez, nunca será levada a cabo", entendendo que esta sociedade planetária ou mundializada é fruto de avanços e retrocessos humano-naturais ao longo do projeto de construção da Terra, tal como ela é hoje. Neste sentido, a ideia de meio ambiente está atrelada a concepção de que o homem é tanto natural quanto a natureza, hoje, é humanizada, no sentido de que os avanços técnico-científicos do tempo presente permitem ao homem o alcance dos mais longínquos lugares onde acredita-se que a natureza seja intocada (a ideia de primeira natureza), mas tão vulnerável quanto qualquer floresta urbana ou mata ciliar em áreas de expansão agrícola e pecuária.

A proposição de diálogo que buscamos tecer aqui, a partir do entendimento de meio ambiente, é a constatação de que, para uma leitura crítica da Geografia na contemporaneidade, não há como conceber homem como sujeito e natureza como objeto, pois são dimensionalidades estritamente associadas e consorciadas nas narrativas locais-globais que são construídas na contemporaneidade. A crise socioecológica, tal como argumenta Leff (2009), ou socioambiental, como afirma Mendonça (2001), expõe a necessidade emergencial de outra postura, outra consciência, outras leituras ativas de mundo que desvirtuem a lógica predatória engendrada pelo capitalismo. Surge a necessidade de se fomentar uma cidadania ecológica, uma cidadania planetária, ou uma ecocidadania (PADILHA et al, 2011).

É em meio a este cenário de crise, de colapso e de risco, como argumenta Costa Lima (2008), que emerge a importância de se reformular a condição humana no projeto de sociedade na busca por sua reintrodução na natureza, agora não como dominador, mas como partícipe de sua regeneração e mobilizador de práticas interventivas que venham a tornar possível o equilíbrio dos processos ecológicos, detendo a perda de biodiversidade em escala local-global. Cremos que a Educação Ambiental tem a potencialidade disto, concordando com o que afirma Loureiro (2008, p. 69), quando menciona que a Educação Ambiental “[...] contribui para a tentativa de implementação de um padrão civilizacional e societário distinto do vigente, pautado numa nova ética da relação sociedade-natureza".

De mesma maneira, a Geografia escolar divide esta preocupação e interesse formativo com a EA, no sentido de uma outra conjectura acerca do projeto de sociedade em vigência e da cidadania, enquanto expressão de um projeto de sociedade democrático e que necessariamente precisa estar pautado numa ótica socioambientalmente reflexiva. No entanto, as práticas desenhadas e materializadas no chão da formação em Geografia ainda conservam uma didática que pouco evoca sentido para um ensinar-aprender crítico-reflexivo, ou seja, um aprendizado cujos princípios norteadores são as habilidades críticas e reflexivas. 
Pensamos ser necessário criar práticas educativas geográficas que ampliem a compreensão da realidade não apenas como ela se apresenta, mas sua internalidade, aquilo que está para além da visão, passando ao campo da leitura e compreensão do que se observa. Isto permite formular proposições de como queremos que ela possa ser transformada. Esta ação didática, como argumenta Rivera (2012, p. 35), perpassa por essa tonificação crítica e reflexiva, que corrobora com aquilo que estamos propondo para a convergência entre educação geográfica e Educação Ambiental.

É uma ação da geografia escolar que deve ser realizada com um tom analítico, crítico e criativo. Isso implica abordar a realidade no que se aprecia e o que ela esconde, mais além do que se vê. Então, é necessário não vislumbrar-se com o que se vê, mas sim ir em busca das internalidades, de tal maneira que se possa elaborar um ponto de vista sobre o que se revela em aparência e construir uma explicação crítica do que se observa e das razões subjacentes que o explicam.

Face ao exposto, verifica-se a urgência em pensar numa didática para a Geografia que seja permeada por um diálogo com a Educação Ambiental, partilhando da necessidade de formular por meio deste campo disciplinar em diálogo com este tema transversal a ecocidadania, caminhando por entre os meandros de uma trajetória ecoformativa, que não se limite a apreensão da sociedade apenas como um projeto societário formulado pelo/para o homem, mas um projeto de sociedade que problematiza as questões socioambientais inerentes à construção de qualquer projeto societário e, ao fazer isto, possibilite aos sujeitos a coletivização de uma consciência solidária, coparticipante e corresponsável. E, nisto, atingir um patamar de ecossociedade, centrada na permanente problematização e proposição de caminhos que viabilizem formas outras de ser-estar no mundo em relação a práticas socioecologicamente transformadoras.

Pensamos também acerca da necessidade de se formular uma outra relação com o saber geográfico, tanto por parte dos professores quanto por parte dos alunos. Esta nova relação precisa estar pautada num arranjo crítico-reflexivo que construa uma teia de sentidos e significados acerca da relação sociedade-natureza, onde o acontecer da humanidade está em permanente estado de vir a ser e onde as práticas sociais-políticas-econômicas-culturais se movimentam. Assim, não se pode conceber o saber ambiental exteriorizado ao saber social, como duas dimensionalidades no ensino de Geografia e na formação de professores para este campo disciplinar, é preciso uma dialogicidade de saberes para ensinar-aprender em Geografia na contemporaneidade (BOTÊLHO; SANTOS, 2017), fugindo de compartimentações e 
estruturas de saber que não invocam o cotidiano, a empiria, a subjetividade e a reflexividade como estratégias norteadoras de uma Geografia escolar para o século XXI.

Ao passo em que a problemática socioambiental se agrava e se complexifica, verifica-se a proporcional importância em se propor para a escola uma formação ecocidadã, ou uma ecoformação, que permita aos sujeitos em situação de ensino e aprendizagem, professores e alunos, uma educação que valorize a vida e não apenas as estruturas normativas, os de conteúdos de ensino. Vida que emerge do cotidiano, permeado por uma sabedoria popular que precisa ser destacada nos roteiros das práticas escolares e nas trajetórias de aprendizagem, tanto na educação básica, nas escolas, quanto no ensino superior, na formação dos profissionais do ensino.

Neste sentido, conforme apontamentos de Botêlho (2017), a ecocidadania evoca na escola a busca pela alteridade, pela solidariedade, pela cooperação, pela coletividade, pelo respeito às diferenças, pelo amor à terra, enquanto chaves pedagógicas para um processo ecoformador que permita extrapolar as fronteiras de um ensino unilateral, transmissivo e pautado numa racionalidade instrumental, cujo destino é sempre o silencio dos sujeitos em nome de uma aprendizagem única e exclusivamente pensada como ferramenta para o trabalho intelectual e mercadológico, e não como mecanismo emancipatório para tempos em que é preciso agir no mundo.

\footnotetext{
Para construir visões de mundo, sociedade e natureza, que se interponham a lógica segregadora, antiemancipatória e antisubjetiva, é necessário que o diálogo se torne um mecanismo de ação social, educacional e política, na medida em que permite a construção de espaços de usufruto democrático por todos os sujeitos sociais, que se desafiam na busca por melhores condições de vida e bem estar social. (BOTÊLHO, 2017 , p. 57)
}

Diante das proposições de encontro dialógico entre a Educação Ambiental, na qualidade de temática ecoformadora que possibilita a ecocidadania, com a educação geográfica, lançamos a necessidade contemporânea de tecer fios outros para as práticas escolares em Geografia, mas que também estão alinhadas às práticas no âmbito da formação de professores de Geografia. Ora, não há como conceber apenas um ensino escolar que mergulhe na complexidade ecoformativa, na busca por rupturas com processos formativos silenciadores, sem igualmente buscar uma formação de professores que também esteja comprometida com as bases teóricometodológicas do tempo presente, rompendo com ciclos viciosos de ensino-aprendizagem que não mais correspondem ao que formulamos para este tempo e cenário de crise. 
Sentimentos, pensamentos e expressões da individualidade são tolhidos e ignorados na escola, assim como os conhecimentos são isolados e divididos como se não pudessem possuir relações entre eles e isso, no ambiente educacional, se apresenta numa desvalorização do humano e num planejamento pedagógico que se foca em disciplinas afastadas entre si e da dimensão integral do sujeito. Logo, é preciso repensar toda a formação que envolve educação, desde a formação de docentes até a oferecida aos alunos, dentro de uma perspectiva mais ampla e coerente com a sociedade e aquilo que esta espera dos seus cidadãos. (AIRES; SUANNO, 2018, p. 238)

De mesma maneira, o diálogo de saberes, proposto por Leff $(2009 ; 2012)$, pauta uma sabedoria que visa rupturas com estruturas de saber normativas, que em nada encontram lugar na cotidianidade dos sujeitos sociais em formação, assim também como não conseguem, no âmbito da formação de professores de Geografia, se materializar em uma formação profissional que encaminhe uma formação escolar outra, que lance as bases de uma educação transformadora de realidades, munindo os sujeitos de mecanismos de ação-reflexão que norteie a reconstrução da sociedade em crise. A emergência de uma sabedoria geográfica, que aconteça por intermédio de processos ecoformadores geradores da ecocidadania, advém da capacidade de diálogo entre saberes sociais e ambientais, na conquista de uma consciência socioambiental

(BOTÊLHO, 2017) que modifique lógicas de ensino pautadas em chaves pedagógicas tecnicistas (produtivismo, competividade, mercado de trabalho, meritocracia etc.). Nosso interesse, propondo uma sabedoria geográfica, é a feitura de chaves pedagógicas críticoreflexivas para um ensinar e aprender Geografia que se mantenha em diálogo com a realidade cotidiana dos indivíduos que aprendem socialmente (JACOBI, 2015) para agir cotidianamente.

Esta sabedoria geográfica está permeada não apenas de saberes, mas de pertencimento, de afetividade, de intersubjetividade, de compromisso, de valores que extrapolam a dureza dos processos de ensino e aprendizagem que se centram em conteúdos engessados e práticas obsoletas. Estamos falando de uma sabedoria conduzida por um conjunto de habilidades e competências, do professor e dos alunos, geograficamente adjetivadas, mas também de questões outras que estão em acontecimento na vida dos sujeitos. Desta forma, estamos falando também de mais que um saber social e ambiental, mas um saber-vida, vida cotidiana, vida coletiva, vida na Terra. Uma educação geográfica que valorize a vida, ecoformando professores e alunos, na escola a nas instituições de ensino superior, conduzindo-os às práticas ecocidadãs.

A educação geográfica do século XXI não mais se direciona ao entendimento de fenômenos, e se sua natureza é social ou ambiental, classificando e estereotipando o saber, mas uma leitura contextual local-global que situe os indivíduos no descobrimento e na intervenção na realidade vivida. Realidade que é plural, que é multirreferencial, e a qual urge por sujeitos sociais que a compreendam como tal. Como afirmam Franco e Pimenta (2016), é preciso cogitar 
uma didática multidimensional, cujo propósito é suscitar o entendimento da dinamicidade dos fenômenos, ao passo em que compreende as particularidades que o compõe, e assim suscitar visões pluralistas sobre o mesmo por meio de um pensar-agir crítico-reflexivo, que compreenda o mundo como teia, como corpo complexo. Para compor esta conjuntura de proposições formativas, acreditamos ser necessário formular um estreitamento com a Educação Ambiental, com processos ecoformadores que deságuam na ecocidadania, e fazemos isso elencando chaves pedagógicas, baseadas em Gutiérrez e Prado (2013), que possibilitem formular contextualmente algumas proposições didáticas para o ensino escolar e profissional de Geografia.

\section{ECOFORMAÇÃO E ECOCIDANIA PARA UMA OUTRA GEOGRAFIA ESCOLAR: as chaves pedagógicas}

Estamos diante de um desafio complexo, sobretudo pelo fato de entendermos o quão cansativo é formular perspectivas teóricas acerca dos desdobramentos das atividades de ensino, enquanto falta uma dimensão prática, que contribua para mudanças substanciais na forma como os sujeitos formadores mobilizam suas práticas e pensam sobre elas. Pensamos que, ao propor a ecoformação, como caminho a seguir, e a ecocidadania, como objetivo que se faz ao caminhar, estamos mirando um ensino-formação que lida com as necessidades deste século, necessidades ímpares na trajetória da humanidade.

Nunca em todo este tempo de processo de constituição das antropossociedades em diversas contextualidades, e também na projeção global destas, se contestou a ineficácia dos processos educativos escolares e acadêmicos, sobretudo os de natureza pública, ou seja, oferecidos pelo Estado. Isso se deve ao fato de o próprio Estado fazer-se ausente, esquecendose de sua incumbência na garantia do acesso e permanência do povo à educação de qualidade, como prevê a Declaração Universal dos Direitos Humanos (UNESCO, 1998), afirmando em seu $26^{\circ}$ artigo no primeiro parágrafo que

Todo ser humano tem direito à instrução. A instrução será gratuita, pelo menos nos graus elementares e fundamentais. A instrução elementar será obrigatória. A instrução técnico-profissional será acessível a todos, bem como a instrução superior, esta baseada no mérito (p. 5)

Estamos falando de um direito fundamental ao desenvolvimento da humanidade e do gozo das liberdades individuais-coletivas que constituem as democracias modernas. Mas aonde estamos indo com estas colocações? Queremos cogitar a ideia da necessidade de não apenas 
garantir a educação dos povos da Terra, mas permitir uma educação que lhes ofereça uma perspectiva de futuro, ao passo em que vislumbramos a negativação de um futuro, dado o contexto de crise, como já argumentamos anteriormente.

Estamos imersos em problemáticas socioambientais que se espraiam por todos os continentes e afetam todos os povos, os mais lembrados e os mais esquecidos, os mais ricos e os mais pobres. No entanto, os mais ricos enriquecem ainda mais ao subjugarem os mais pobres à opressão capitalista em nome da marcha pelo progresso técnico-científico-informacional. Os que mais sofrem são aqueles a quem menos é dado um conjunto de oportunidades de mudança.

As desigualdades se ampliam e se fortalecem, num movimento quase que invisível, pois tende a mascarar realidades empobrecidas, enquanto enaltece um life style do mundo moderno, globalizado, capitalizado e homogêneo, do ponto de vista cultural. Saberes e práticas tradicionais perdem seus espaços e sobrevivem apenas na memória do que restou de seus representantes. E é para isto que a indicamos a necessidade de uma ecoformação, para dar conta dos desafios globais do século XXI na busca pela ruptura com este paradigma do silêncio, do empobrecimento, da morte dos ecossistemas e da vida, da crise permanente.

Atrelados a isto, somamos a urgência de uma sabedoria geográfica que mobilize os sujeitos a tematizar crítico-reflexivamente os problemas que os assolam cotidianamente, oferecendo a estes a oportunidade de construírem autonomamente os mecanismos múltiplos de intervenção, de reinvindicação, de luta e conquista por seus direitos. Cidadania! Nas tramações que estamos aqui a realizar, propomos uma educação ecoformadora que constitua o caminho para uma cidadania planetária, ou ecocidadania, e que nesta a Geografia escolar torne-se mais que um compêndio de informações desconexas das realidades dos indivíduos, mas um eixo formador que propicie aos aprendentes a esperança por dias melhores. Talvez seja isto que Morin, Ciurana e Motta (2003, p. 99) expressam ao afirmar que “A educação planetária deve propiciar uma mundologia da vida cotidiana".

Esta sociedade-mundo em crise precisa de uma educação que problematiza a crise, não que faça parte dela, que a alimente, enquanto alienados e desconectados uns dos outros estão os sujeitos sociais. Por isto, firmamos que a ecoformação deva ser orientada, no plano pedagógico, por cinco chaves pedagógicas, a saber: alteridade, coletividade, dialogicidade, afetividade e responsabilidade. Para chegar a tais chaves, dialogamos com Gutiérrez e Prado (2013), Leff (2009), Loureiro (2003) e Padilha (2004), além de outros autores associados, afinal não se pode chegar a tal conclusão sem cogitar outras aberturas dialógicas para formular tais chaves. Vale ressaltar que nenhuma chave se sobrepõe a outra, assim como não há um sequenciamento lógico para que uma se constitua e abra caminho para a próxima. No entanto, 
algumas possuem um caráter mais central e funcionam como conexão entre outras, dada sua importância. Entendemos as chaves pedagógicas como princípios formativos indissociáveis,

pautados num processo ininterrupto de construção de aprendizagens socioambientais que valorizam a vida e o cotidiano, assim como dialogam amplamente com os temas e conteúdos disciplinas que estruturam a corporeidade das ciências pedagogizadas nos currículos escolares.

A alteridade é a capacidade de o indivíduo colocar-se no lugar do outro. É uma das chaves mais centrais neste processo, pois constitui um princípio ecoformador capaz de possibilitar aos sujeitos a compreensão do outro não por meio de si, mas o reconhecimento e respeito ao outro como ele o é. Neste sentido, estamos pondo em questão a empatia, a necessidade de compreender que o outro é diferente de mim, e por isto mesmo ele é necessário ao mundo.

Não há cidadania planetária/ecocidadania, sem a presença do outro como ele é. Não há sociedade-mundo sem a convivência, para além da coexistência, com os diferentes. Somos unomúltiplos. Somos uno, como sociedade que caminha junto no processo de hominização, e múltiplos, pois variadas são as percepções e variadas são as leituras e escritas de mundo dos indivíduos. A escola, enquanto este espaço inicial de fomento à vida, necessita fomentar a alteridade. A formação de professores carece da alteridade como princípio norteador, para além da burocracia pedagógica, embebida em metodologias que não constituem diálogos, mas certamente compreendendo as diferenças como entrelugar para a problematização geográfica que lance as bases desta sabedoria de que falamos.

A coletividade emerge como outra chave pedagógica de suma importância. Reconhecidas as diferenciações entre os sujeitos do processo pedagógico, assim como reconhecida a potencialidade formadora que habita na convivência destes diferentes, precisamos agora promover os espaços coletivos onde ocorrem as confluências entre esses sujeitos que estão em busca de aprender a ser e estar no mundo, mudando-o, combatendo o risco e lutando por sua dignidade.

Como pensar em cidadania planetária/ecocidadania sem a coletividade? Impossível. A educação depende da coletividade, assim como a sociedade-mundo em colapso eminente provocado pelo avanço desta crise socioambiental tanto requer uma coletividade para rompêla. A coletivização requer a presença da escola, a mediação de processos que permitam a relacionalidade dos sujeitos nas tramações cotidianas no chão da escola e para além dele. É na escola que é possível pensar em sociabilidades que se coletivizam e constroem um projeto societário menos desigual e excludente, ao tornar-se impregnado de coletividade. 
Educar significa, ainda, fazer com que os educandos e as educandas tomem para si próprios, sabendo-se integrantes da coletividade, a responsabilidade pelos rumos e pela saúde do planeta, sabendo-se cidadãs e cidadãos do mundo. "Não nascemos seres humanos, nós nos tornamos seres humanos" (MELLO, 2009). Portanto, ser um ser humano não está determinado quando nascemos, mas é uma possibilidade que depende das nossas ações e diálogos com outras pessoas ao longo de nossas vidas (PADILHA et al, 2011, p. 149)

E por falar em "diálogos com outras pessoas ao longo de nossas vidas", conforme destacado no trecho retirado da obra de Paulo Roberto Padilha et al, a chave pedagógica ecoformadora da dialogicidade nos demonstra sua importância. Talvez seja ela uma chave mestra, ou seja, que está alinhada com todas as outras, permitindo a convergência destas. Porém, cremos que há um lugar específico para ela. O diálogo, no sentido freiriano da palavra, como Botêlho (2017) destaca, requer mais que uma conversa, não é algo informal, descontínuo, que tenha início e fim. É algo que se dá continuamente, em diferentes espaços, por meio de diferentes indivíduos e que constitua diversos eixos dialógicos construtores da sociedade- mundo.

\footnotetext{
O diálogo entre os homens e entre os homens e o mundo, permite a construção e a prática da liberdade, tendo em vista que sua mobilização insurge à opressão e a oposição ao diálogo, possibilitando o enfrentamento e a insurgência a não permissividade da prática solidária e da autoafirmação dos homens (BOTÊLHO, 2017, p. 57)
}

Portanto, a dialogicidade norteia a confecção conjunta, coletiva, de um projeto societário baseado na diversidade, no respeito, no amor, como destaca Freire (1997). Os homens se coletivizam, se transformam, mudam a sociedade com base no diálogo, freando o avanço da barbárie, do caos, da crise, da opressão. É no diálogo que se fazem os homens. É no diálogo que os processos educativos tomam forma, quer seja no planejamento pedagógico engendrado para mapear que prática ocorrerão em dado período de tempo quer seja no cotidiano destas práticas e da convivência coletiva dos sujeitos. E é pelo diálogo que a afetividade emerge.

A afetividade constitui uma chave pedagógica ecoformadora importante para este século. Estamos falando de uma educação que não priorize apenas conteúdos e formas de ensinar pautadas na técnica vazia, fria, transmissiva. Estamos falando do encontro dos diferentes que se reconheçam, dialoguem, construam uma coletividade e mantenham entre si uma afetividade. $\mathrm{O}$ vazio do afeto na formação dos professores e na formação escolar é o retrato de um aplicacionismo tecnicista que prioriza o saber a ser ensinado, mas não consegue dar conta de como é possível construir o espaço para que este saber seja ensinado. A afetividade é a resposta. 
Num tempo de frieza, de endeusamento das tecnologias e seus desdobramentos para práticas educativas, ditas inovadoras, em Geografia ou em qualquer outro componente curricular, a afetividade tem se perdido cada vez mais nestas tramações no cotidiano escolar. Além disso, o anseio de setores e atores políticos pela implantação de ensino à distância no ensino fundamental e médio parece ser um outro caminho a anular a afetividade, a coletividade, a dialogicidade. Observamos aqui que nenhuma tecnologia substitui a formação humana baseada no diálogo constitutivo da alteridade e da coletividade, permeadas pela afetividade. Nenhuma! Assim como afastar as crianças e jovens das escolas, colocando-os para estudar em frente a um computador, levando-os a escola apenas para tirar dúvidas, caso seja necessário, também não é solução contemporânea, é retrocesso. A escola precisa de valorização urgencial de seus processos e atores, permitindo a multiplicação de práticas formadoras afetivas.

Por fim, cremos que a responsabilidade é gerada por intermédio de toda uma conjuntura de processos educativos que aproximam os sujeitos, coletivizam formas de pensar-agir, constroem diálogos ininterruptos e afetivos capazes de formular aprendizagens socioambientais pautadas na reconfiguração de uma sociedade-mundo em crise. A reponsabilidade é algo que se dá do individual para o coletivo, num sentido de ida-vinda, diálogo, criando possibilidades interventivas que modificam os processos de deterioração da vida humana e degradação ambiental que já temos observado.

A responsabilidade é algo partilhado, que nasce de motivação individual para a mudança, porém ela precisa atingir um plano coletivo, na medida em que os agentes do espaço se tornem corresponsáveis pela mudança que querem ver/ser no mundo. Talvez, numa mirada final, a responsabilidade apareça mais como objetivo que como chave do processo, porém ela conduz o firmamento do compromisso dos sujeitos aprendizes, quer alunos quer professores, em tornar real uma escola que atua na construção da alteridade, da coletividade, da dialogicidade, da afetividade sociopedagógica, ou seja, aproximando a dimensão social de uma dimensão pedagógica, ao compreendermos que é preciso conceber os processos educativos a partir de uma lógica anti-separatista entre sociedade e pedagogias condutoras das práticas escolares.

Nisto, evidencia-se uma sabedoria geográfica que, por mais assim adjetivada, tem em seu cerne não apenas conteúdos de Geografia, mas é trafegada por um arcabouço mais amplo de questões que são inerentes a formação sociopedagógica do tempo presente. Precisamos descortinar uma sabedoria escolar que transponha a alienação que se impõe por meio do massivo acesso a informação sem que a criticidade e reflexividade acompanhem este mesmo movimento. Desta feita, reafirmamos o sentido e a necessidade de a Geografia compor o rol de 
disciplinas escolas e, mais que isso, de saberes para a vida que levam os sujeitos sociais em formação a se afirmarem como partícipes das dinâmicas sociais cotidianas locais-globais.

As chaves pedagógicas aqui delineadas e defendidas têm um caráter não fixado, podendo ser adaptadas ao mais diversos níveis, formas e realidades de ensino, muito embora são essenciais princípios formativos para a docência na educação básica e valores que precisam ser reiterados na prática escolar. Não que estas devam ser tratadas como conceitos da formação dos professores e da formação escolar, mas, de orem pedagógica, estas chaves precisam ser fios condutores de leituras analíticas crítico-reflexivas que lançam as bases de uma sabedoria, que é geográfica, que é histórica, que é sociológica, que é filosófica etc.

Diante dos enfrentamentos socioambientais contemporâneos, não nos resta dúvida em reafirmarmos a necessidade de romper com lógicas propedêuticas na construção dos saberes e em sua mobilização prática, por intermédio de uma trajetória ecoformativa que nos leva à ecocidadania. E é a isto que nos remetemos com veemência, reiterando fortemente uma ecoformação balizada por práticas ecocidadãs que surgem coletivamente, são espaço para diálogos, aproximam afetivamente os sujeitos enquanto reconhecem suas diferenças e constituem a alteridade, responsabilizando coletivamente a sociedade a buscar mecanismos de intervenção solidária ao caos socioambiental e provocar mudanças para que a pátria Terra, pátria comum a todos nós, tenha um futuro.

\section{INTERMITÊNCIAS CONCLUSIVAS}

As conclusões postas aqui são de caráter transitório, intermitente, uma vez que nossas reflexões mudam conforme um conjunto de questões que podem mudar, sobretudo pelo fato de ser o próprio processo reflexivo de caráter humano e o humano é inacabado. O processo pedagógico, formativo escolar e acadêmico é inacabado e requer uma permanente condição de vir a ser, de reflexão situada e propositiva em fluxo.

Situamos a Educação Ambiental como um tema, eixo, trajetória de grande importância para a sociedade-mundo contemporânea, no enfrentamento das problemáticas socioambientais que se ampliam e prejudicam cada vez mais o prosseguimento do processo de hominização, de humanização e de educação. De igual modo, a Geografia, em sua interface pedagógica, também oferece elementos para a construção de uma sociedade democrática, horizontalizada e que cria mecanismos de intervenção local-global para transformar as tramações contemporâneas societárias que estão sendo construídas. 
A ecocidadania e a ecoformação emergem neste caminho, nestes roteiros oxigenados e contemporâneos, e nutrem perspectivas e tendências contemporâneas que venham a combater os retrocessos da crise socioecológica, que são humanitários, políticos, sociais, econômicos. A educação vem ao encontro disto, na medida em que busca também combater os problemas sociais e ambientais que estão em acontecimento, mas precisa ser nutrida de questões, tais como as que estamos propondo e pensando neste texto, que possam emergir no seio deste debate contemporâneo e na construção de propostas que lutam por justiça social e ambiental e transformações efetivas na sociedade-mundo que objetivamos.

\section{REFERÊNCIAS}

AIRES, B. F. C.; SUANNO, J. H. A criatividade no âmbito da ecoformação: Uma perspectiva a partir da complexidade e da Transdisciplinaridade. Revista Signos, Lajeado, v. 39, n. 1, 2018.

BECK, U. Risk society. London: Sage Publications, 1992.

BOTÊLHO, L. A. V.; SANTOS, M. F.; SANTOS, F. K. S. S. A educação ambiental e a geografia escolar: dimensões curriculares, possibilidades e desafios contemporâneos.

Caminhos de Geografia, Uberlândia, v. 17, n. 59, p. 126-143, 2016.

BOTÊLHO, L. A. V.; SANTOS, F. K. S. Ecocidadania, educação ambiental e ensino de Geografia. Geografia Ensino e Pesquisa, Santa Maria, v. 21, n. 1, p. 54-64, 2017.

BOTELHO, L. A. V. A ecocidadania como princípio formativo e propositivo: diálogos necessários para a construção de uma escola cidadã. 2017. 195 f. Dissertação (Mestrado em Geografia) - Programa de Pós-graduação em Geografia, Universidade Federal de Pernambuco, 2017.

ESTEVES, C. J. de O. Risco e vulnerabilidade socioambiental: aspectos conceituais.

Caderno IPARDES, Curitiba, v. 1, n. 2, p. 62-79, 2011.

FRAGA, L. A. de. Educação Ambiental e valores: recriando espaço para uma razão sensível. In: BONOTTO, D. M. B.; CARVALHO, M. B. S. da S (Orgs.). Educação ambiental e valores na escola. 1. ed. São Paulo: Cultura Acadêmica, 2016, p. 139-154.

FRANCO, M. A. S.; PIMENTA, S. G. Didática multidimensional: por uma sistematização conceitual. Educação \& Sociedade, Campinas, v. 37, n. 135, p. 539-553, abr-jun, 2016.

FREIRE, P. Pedagogia da esperança: um reencontro com a Pedagogia do oprimido. Rio de Janeiro: Paz e Terra, 1997.

GUTIÉRREZ, F.; PRADO, C. Ecopedagogia e cidadania planetária. 3. Ed. São Paulo: Cortez Editora, 2013.

JACOBI, P. Meio ambiente, riscos e aprendizagem social. Cadernos de Pesquisa: Pensamento Educacional, Curitiba, v. 10, n. 26, p. 346-364, set/dez 2015. 
LEFF, E. Aventuras da epistemologia ambiental: da articulação das ciências ao diálogo de saberes. São Paulo: Cortez Editora, 2012.

LEFF, E. Complexidade, Racionalidade ambiental e Diálogo de saberes. Educação e Realidade, Porto Alegre, vol 34(3), p. 17-24, set./dez. 2009.

LIMA, G. F. da C. Crise ambiental, educação e cidadania: os desafios da sustentabilidade emancipatória. In: In: LOUREIRO, F. B.; LAYARARGUES, P. P.; CASTRO, R. S. de (orgs.). Educação ambiental: repensando o espaço do cidadão. São Paulo: Cortez, 4. ed. 2008. p. 109-141.

LOUREIRO, C. F. B. (Org). Cidadania e meio ambiente. Salvador: Centro de Recursos Ambientais, 2003. 168p.

LOUREIRO, C. F. B. Educação ambiental e movimentos sociais na construção da cidadania ecológica e planetária. In: LOUREIRO, F. B.; LAYARARGUES, P. P.; CASTRO, R. S. de (orgs.). Educação ambiental: repensando o espaço do cidadão. São Paulo: Cortez, 4. ed. 2008. p. 69-98.

MENDONÇA, F. Geografia socioambiental. Terra Livre, São Paulo, n. 16, p. 139-158, 2001.

MORIN, E.; CIURANA, E.-R.; MOTTA, R. D. Educar na era planetária: o pensamento complexo como método de aprendizagem pelo erro e incerteza humana. São Paulo: Cortez, 2003.

NARDY, M.; DEGASPERI, T. C. Educação Ambiental e cidadania: desafios para a construção do pensamento glocal. In: BONOTTO, D. M. B.; CARVALHO, M. B. S. da S (Orgs.). Educação ambiental e valores na escola. 1. Ed. São Paulo: Cultura Acadêmica, 2016, p. 119-137.

PADILHA, P. R. Currículo Intertranscultural: Novos itinerários para a educação. São Paulo: Cortez/Instituto Paulo Freire, 2004.

PADILHA, P. R. et al. Educação para a Cidadania Planetária: currículo interdisciplinar em Osasco. São Paulo: Editora e Livraria Instituto Paulo Freire, 2011.

REIGOTA, M. Meio ambiente e representação social. São Paulo: Cortez, v. 12, 8. ed. 2008.

RIVERA, J. A. S. A Geografia escolar no debate epistemológico e didático do mundo contemporâneo. In: CASTELLAR, S. V.; CAVALCANTI, L. S.; CALLAI, H. C. (orgs.).

Didática da Geografia: aportes teóricos e metodológicos. São Paulo: Xamã, 2012, p. 27-44.

SANTOS, M. A natureza do espaço: técnica e tempo, razão e emoção. São Paulo: Editora da Universidade de São Paulo, 1996.

SOFFIATI, A. Fundamentos filosóficos e históricos para o exercício da ecocidadania e da ecoeducação. In: LOUREIRO, F. B.; LAYARARGUES, P. P.; CASTRO, R. S. de (orgs.). 
Educação ambiental: repensando o espaço do cidadão. São Paulo: Cortez, 4. ed. 2008. p. 2368 .

SUERTEGARAY, D. M. A. Geografia e Interdisciplinaridade. Espaço Geográfico: interface natureza e sociedade. Geosul, Florianópolis, v. 18, n. 36, p. 43-53, jan/jun de 2003.

VESENTINI, J. W. Geografia, Natureza e sociedade. 4. ed. São Paulo: Contexto, 1997. (Repensando a Geografia).

UNESCO. Declaração Universal dos Direitos Humanos. Brasília: Representação da UNESCO no Brasil, 1998. 